\title{
Prevalence of HIV, Syphilis, Hepatitis B and C in pregnant women at a maternity hospital in Salvador
}

Jacielma de Oliveira Freire 1

iD https://orcid.org/0000-0002-4586-8087

Jaqueline Bohrer Schuch 2

iD https://orcid.org/0000-0002-2195-4407

Mariana Freire de Miranda 3

(iD https://orcid.org/0000-0003-3861-6081

Vinícius Serafini Roglio 4

(iD) https://orcid.org/0000-0002-6962-233X

\author{
Helita Tanajura 5 \\ iD https://orcid.org/0000-0002-5578-4557 \\ Ana Gabriela Lima Bispo de Victa 6 \\ (iD) https://orcid.org/0000-0002-9442-1345 \\ Lisia von Diemen 7 \\ (iD https://orcid.org/0000-0001-9228-7114
}

\footnotetext{
1,5,6 Maternidade Climério de Oliveira. Universidade Federal da Bahia. Salvador, Bahia, Brasil.

2,7 Programa de Pós-Graduação em Psiquiatria e Ciências do Comportamento. Faculdade de Medicina. Hospital de Clínicas de Porto Alegre. Universidade Federal do Rio Grande do Sul. Porto Alegre, RS, Brasil. Rua Prof. Álvaro Alvim, 400. Porto Alegre, RS, Brasil. CEP: 90.040-060. E-mail: jaqbs.bio@gmail.com

3 Universidade Salvador. Salvador, BA, Brasil.

${ }^{4}$ Centro de Pesquisa em Álcool e Drogas. Hospital de Clínicas de Porto Alegre. Universidade Federal do Rio Grande do Sul. Porto Alegre, RS, Brasil.
}

\begin{abstract}
Objectives: to calculate the prevalence and rate per 1,000 live births of sexually transmitted infections (STI) in pregnant women at a public maternity hospital in Salvador.

Methods: this descriptive, cross-sectional study retrospectively collected data from compulsory notifications and medical records of pregnant women with STI seen at a maternity hospital in northeastern Brazil between 2014 and $2017(n=520)$. Prevalence and rate per 1,000 live births were estimated for hepatitis B, hepatitis $C, H I V$, and syphilis. Associations between STI and other clinical and sociodemographic variables were investigated.

Results: most pregnant women were born and resided in Salvador, presented a mean age of 26.4 years, self-reported mixed-race and had unplanned pregnancies. Prevalence and rates per 1,000 live births were, respectively: $0.26 \%$ and 3.39 for hepatitis $B, 0.06 \%$ and 0.79 for hepatitis $C, 0.47 \%$ and 6.23 for HIV, and $2.46 \%$ and 32.2 for syphilis.

Conclusion: higher prevalence and rates of infection per 1,000 live births were seen at the maternity hospital in northeastern Brazil compared to official data provided by the Brazilian government, notably with regard to HIV and syphilis. The appropriate epidemiological notification of STI, especially in pregnant women, enables the elaboration of effective preventive strategies incorporating specific sociodemographic and clinical characteristics.
\end{abstract}

Key words Pregnancy, Viral hepatitis, HIV, Syphilis, Sexually transmitted infections

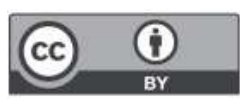




\section{Introduction}

Sexually transmitted infections (STI), especially hepatitis B and C, HIV and syphilis, constitute a major public health problem worldwide, with important implications on the health of pregnant women, their sexual partners and newborns. STI have been associated with spontaneous miscarriages, premature birth, low birth weight and other complications specific to infectious agents. ${ }^{1}$ In Brazil, notably the northeastern region, an increasing prevalence of STI has been reported in the general population. Although the serological investigation and notification of hepatitis B and C, HIV and syphilis are mandatory during pregnancy, the sub-notification of cases occurs in some regions of the country. $2-4$

The transmission routes of Hepatitis B (HBV) and $\mathrm{C}(\mathrm{HCV})$ are similar. In addition to sexual and parenteral transmission, vertical transmission (VT) from mother to fetus during pregnancy or childbirth is another relevant transmission route. 5 Evidence shows that VT of HBV can result in an unfavorable evolution of this disease in newborns, potentially inducing significant inflammatory processes and altered liver enzyme levels, eventually progressing to cirrhosis.6,7 Despite the availability of vaccines, around 233,000 cases of HBV were confirmed between 1999 and 2018 in Brazil, with most notifications occurring among young adults aged between 25-39 years. Data from this same period also indicate that pregnant women account for $10.4 \%$ of all HBV cases. 4 In addition, HCV has been associated with several highly relevant clinical conditions during pregnancy: gestational diabetes, preeclampsia, cholestasis and altered liver enzyme levels. ${ }^{8-11}$ An epidemiological bulletin issued by the Brazilian Ministry of Health $(\mathrm{MoH})$ reported 228,000 confirmed cases of hepatitis $\mathrm{C}$ between 1999 and 2018. While data on the occurrence of $\mathrm{HCV}$ infection during pregnancy remain scarce, ${ }^{4}$ a recent study estimated HCV VT risk at 5.8\%. ${ }^{12}$ In newborns, associated clinical manifestations can include asymptomatic infections, liver fibrosis, cirrhosis, carcinoma, and liver enzyme changes. $10,13,14$

The transmission routes of hepatitis $\mathrm{B}$ and $\mathrm{C}$ are similar to HIV, which can progress to Acquired Immunodeficiency Syndrome (AIDS). In Brazil, approximately 247,000 cases of HIV were notified between 2007-2018, with 42,000 cases diagnosed in 2017 alone. In pregnant women, recent data indicate 7,882 cases diagnosed in 2017.3 The VT of HIV can occur during pregnancy, childbirth or in breastfeeding. Late diagnosis during pregnancy can hamper the control of viral load, increasing the risk of HIV transmission to newborns. Upon diagnosis, antiretroviral therapy should be started as soon as possible. Newborns exposed to HIV may present greater susceptibility to bacterial infections, low birth weight and premature birth. ${ }^{7}$

Syphilis, another noteworthy STI, has seen increasing detection rates over the past decade. Around six million new cases have been reported annually worldwide, 15 with almost one million diagnoses in pregnant women, and 22,000 cases of congenital syphilis reported in the Americas. 16,17 In Brazil, almost 120,000 cases of syphilis were notified in 2017; 50,000 occurred in pregnant women. ${ }^{2}$ Inadequate treatment of infection during pregnancy can lead to spontaneous abortion, premature birth and fetal death. Congenital syphilis characterizes a severe clinical condition that can compromise the osteoarticular, neurological, ophthalmological, and cardiovascular systems. 7,15,18,19

The occurrence of STI constitutes a major public health concern, prompting the epidemiological monitoring of severe disease. Pregnant women are of particular interest due to risks to fetal health and the potential for VT. In addition, regular monitoring during pregnancy via prenatal care can facilitate the access of these individuals to intervention. However, relevant discrepancies exist in prenatal healthcare for pregnant women among regions and even within states throughout Brazil. Infection rates reported in different regions or states may not truly reflect the distinctive characteristics of a given city or even local maternity services. It follows that a more precise identification of relevant characteristics in affected groups can lead to the development of more effective prevention strategies. Accordingly, the present study aimed to determine the prevalence and rates of $\mathrm{HBV}, \mathrm{HCV}, \mathrm{HIV}$, and syphilis per 1,000 live births among a population of pregnant women seen at a public maternity service in the city of Salvador, located in the northeastern state of Bahia, Brazil.

\section{Methods}

The present descriptive, retrospective, crosssectional study was carried out in a population of pregnant women with STI seen at the Climério de Oliveira Maternity Hospital - Federal University of Bahia (MCO-UFBA), located in Salvador (BahiaBrazil), between 2014 and 2017. This public maternity hospital serves two districts in Salvador: Barra/Ondina/Rio Vermelho and Centro Histórico (see Mapa de Vinculação de Gestantes, Rede Cegonha). In Brazil, primary health care units are 
responsible for providing prenatal exams and care in accordance with the patient's district of residence. Correspondingly, around 250-300 obstetric procedures are carried out monthly at MCO-UFBA. The present study protocol received approval from the Institutional Review Board of MCO-UFBA (protocol $\mathrm{n}^{\circ}$. 3234904) and was conducted in accordance with the guidelines put forth in the Helsinki Declaration. The confidentiality of all collected patient data was assured at all times.

Information on live births and the total number of pregnant women seen annually at MCO-UFBA was provided by the Epidemiologic Vigilance Service and the Commission for Hospital Infection Control, respectively. All pregnant women seen at the maternity hospital were routinely tested for HBV, $\mathrm{HCV}, \mathrm{HIV}$, and syphilis, in conformity with technical recommendations issued by the $\mathrm{MoH}$ (Ministry of Health). Each positive test result confirmed by a laboratory generated a notification sent to the Notifiable Diseases Information System (SINAN Portuguese acronym), maintained by the MoH. All reported notifications were then sent back to districts, and MCO-UFBA furnished digital copies that were subsequently used for STI data collection purposes. Information regarding each woman's course of pregnancy, sociodemographic characteristics, use of alcohol and/or other drugs, as well as sexual behavior were obtained through the review of hospital medical records.

In all, 16,639 pregnant women were seen at MCO-UFBA between 2014 and 2017; of these, 520 tested positive for at least one of the STI evaluated. Due to a lack of complete information and/or the unavailability of medical records in 2017, sociodemographic data was only available for just over $50 \%$ $(275 / 520)$ of the patients; in these cases, only notifications from SINAN were included in our analysis. Data collection took place between October 2018 and March 2019, considering all available notifications from 2014 to 2017 . A database 20 was built using the Research Electronic Data Capture (REDcap) web-based application. Three investigators were trained in REDcap methodology to ensure standardized data collection. Divergent, missing, or illegible information were registered as "ignored/prefer not to say."

STI prevalence was calculated by dividing the number of pregnant women with each STI by the total number of pregnant women seen at the maternity hospital. Rates of infection per 1,000 live births were extrapolated by multiplying STI prevalence by 1,000. Bivariate analysis compared the presence or absence of each STI with sociodemographic charac- teristics (age at time of notification, race/skin color, marital status, and district of residence) using the chi-square test for association, Fisher's exact test and Student's t-test. All statistical analyses were performed using IBM SPSS v.18 software.

\section{Results}

Most of the pregnant women with STI were born $(n=186,67.1 \%)$ and resided $(n=245,88.4 \%)$ in Salvador. Table 1 lists the demographic characteristics of the participants stratified according to each STI. Mean age was found to be similar among the groups, most women were single $(59.3 \%)$ and selfreported mixed-race $(62.8 \%) ; 92.8 \%$ of all pregnancies were unplanned. Most pregnant women with STI who received care at MCO-UFBA resided outside the institution's designated area of service (59\%). An association between HIV status and skin color $(p=0.018)$ was detected, as more mixed-race individuals tested positive for HIV than those who self-reported skin color as black. Inversely, syphilis was more frequently found in pregnant women who self-reported as black compared to mixed-race $(p=0.007)$.

The overall prevalence of the STI evaluated in the pregnant women seen at MCO-UFBA was 3.12\% between 2014 and 2017. Table 2 lists STI prevalence and rate of infection per 1,000 live births, respectively: $0.26 \%$ and 3.39 for $\mathrm{HBV}, 0.06 \%$ and 0.79 for $\mathrm{HCV}, 0.47 \%$ and 6.23 for HIV, and $2.46 \%$ and 32.2 for syphilis. Interestingly, a dramatic increase in the number of syphilis cases per 1,000 live births was seen, rising from 2.74 in 2015 to 53 in 2016. Although not as expressive, a notable rise in the number of HIV and HBV cases also took place during the study period. HCV prevalence remained stable throughout the time period considered. The number of syphilis cases among pregnant women with any aggravation was $78.7 \%(n=409)$ during the studied period, being HIV the second most frequent $(15.2 \%, \mathrm{n}=79)$.

Cases of coinfection were also analyzed among the pregnant women studied. Among pregnant women with HIV ( $\mathrm{n}=54)$, nine also present syphilis $(16.7 \%, n=9)$. Only one HIV-positive participant was coinfected with HBV, and another with HCV. Among pregnant women with syphilis $(n=196)$, the highest rates of coinfection were found in combination with HIV (4.6\%, n=9), HBV (1.5\%, n=3) and HCV $(1.0 \%, \mathrm{n}=2)$. 


\section{Discussuion}

Epidemiological studies carried out in specific regions throughout Brazil contribute to the elucidation of socioeconomic disparities across the country's regions and cities. Evidence shows that socioeconomic factors are relevant in identifying and quantifying at-risk populations in order to deploy suitable and specific interventions aimed at promoting health awareness and disease prevention. 21 To better represent the findings of the present study, the number of cases of each STI per 1,000 live births at MCO-UFBA was compared to data published by the $\mathrm{MoH}$ considering the state of Bahia, the Northeast region of Brazil and the country as a whole (Figures 1 and 2). A high rate of infection per 1,000 live births was found at MCO-UFBA in comparison to national data, particularly with respect to HIV, HBV, and syphilis. In 2017, HIV seropositivity was 4.1 times more frequent at the maternity hospital than in Brazil, while rates for HBV and syphilis were 11 and 5.7 times higher, respectively. Increasing rates of syphilis among pregnant women evidence a worrisome trend. In 2017 , a rate of 97.8 cases per 1,000 live births indi- cated that approximately $10 \%$ of the pregnant women seen at MCO-UFBA were infected with syphilis. Unfortunately, the Brazilian federal government does not publish official data on HCV infection.

In Brazil, the notification of all cases of infection by HIV, HBV, HCV and Treponema pallidum, the causative agent of syphilis, is mandatory by health authorities throughout the country. 22 Highly rigorous observation of these mandatory disease notification protocols could be a primary reason underlying the differences observed between data published by the $\mathrm{MoH}$ and those reported by the maternity hospital. It is possible that the present findings are indicative of disparities with regard to what should be standard notification procedures. In addition, despite mandatory notification requirements, data provided by the $\mathrm{MoH}$ concerning $\mathrm{HCV}$ in pregnant women remains scarce, which inhibits the implementation of more suitable interventions aimed at controlling the spread of disease.

An increasing prevalence of syphilis, and higher rates of infection per 1,000 live births in pregnant women, were both relevant findings in the present study. Importantly, these trends are observable both

Table 1

Sociodemographic characteristics and associations with STI in pregnant women seen at Climério de Oliveira Maternity Hospital between 2014 and 2017 (Salvador, Bahia-Brazil).

\begin{tabular}{|c|c|c|c|c|c|c|c|c|}
\hline & \multirow[t]{2}{*}{ Age a } & \multicolumn{3}{|c|}{ Self-reported skin color b } & \multicolumn{2}{|c|}{ Marital status b } & \multicolumn{2}{|c|}{$\begin{array}{l}\text { Residence within designated } \\
\text { hospital's region of service }\end{array}$} \\
\hline & & White & Mixed-race & Black & Single & Married c & Yes & No \\
\hline Total $(n=275)$ & $26.4 \pm 6.8$ & $11(4.1)$ & $169(62.8)$ & 89 (33.1) & $150(59.3)$ & $103(40.7)$ & $111(41.0)$ & $160(59.0)$ \\
\hline \multicolumn{9}{|l|}{ HIV } \\
\hline Yes & $26.3 \pm 6.3$ & $2(3.8)$ & $42(79.2) *$ & $9(17)^{*}$ & $29(55.8)$ & $23(44.2)$ & $19(35.8)$ & $34(64.2)$ \\
\hline No & $26.4 \pm 6.9$ & $9(4.2)$ & $127(58.8) *$ & $80(37) *$ & $121(60.2)$ & $80(39.8)$ & $92(42.2)$ & $126(57.8)$ \\
\hline$p$ & 0.913 & & 0.018 & & \multicolumn{2}{|c|}{0.635} & \multicolumn{2}{|c|}{0.439} \\
\hline \multicolumn{9}{|l|}{ Hepatitis B } \\
\hline Yes & $26.4 \pm 6.3$ & $0(0)$ & $23(76.7)$ & $7(23.3)$ & $13(44.8)$ & $16(55.2)$ & $9(30.0)$ & $21(70.0)$ \\
\hline No & $26.4 \pm 6.8$ & $11(4.6)$ & $146(61.1)$ & $82(34.3)$ & $137(61.2)$ & $87(38.8)$ & $102(42.3)$ & $139(57.7)$ \\
\hline$p$ & 0.986 & \multicolumn{3}{|c|}{0.184} & \multicolumn{2}{|c|}{0.109} & \multicolumn{2}{|c|}{0.239} \\
\hline \multicolumn{9}{|l|}{ Hepatitis C } \\
\hline Yes & $29.3 \pm 7.3$ & $1(12.5)$ & $4(50.0)$ & $3(37.5)$ & $6(75.0)$ & $2(25.0)$ & $2(25.0)$ & $6(75.0)$ \\
\hline No & $26.3 \pm 6.7$ & $10(3.8)$ & $165(63.2)$ & $86(33.0)$ & $144(58.8)$ & $101(41.2)$ & $109(41.4)$ & $154(58.6)$ \\
\hline$p$ & 0.184 & 0.429 & & & 0.478 & & 0.478 & \\
\hline \multicolumn{9}{|l|}{ Syphilis } \\
\hline Yes & $26.3 \pm 6.9$ & $8(4.2)$ & $109(57.1)^{*}$ & $74(38.7)^{*}$ & $109(61.2)$ & $69(38.8)$ & $87(45.1)$ & $106(54.9)$ \\
\hline No & $26.7 \pm 6.5$ & $3(3.8)$ & $60(76.9)^{*}$ & $15(19.2)^{*}$ & $41(54.7)$ & $34(45.3)$ & $24(30.8)$ & $54(69.2)$ \\
\hline$p$ & 0.603 & & 0.007 & & \multicolumn{2}{|c|}{0.401} & \multicolumn{2}{|c|}{0.04} \\
\hline
\end{tabular}

Results presented in columns within each STI group as: amean \pm standard deviation and Student's t test for independent groups; bfrequency (\%) and chi-squared test of association.

cMarried or stable union. *adjusted residual > 11.96I. Due to lacking sociodemographic information, bivariate analyses did not include data from 2017. 
Prevalence of syphilis, HIV, hepatitis B and C, as well as number of cases per 1,000 live births in pregnant women with STI seen at Climério de Oliveira Maternity Hospital between 2014 and 2017 (Salvador, Bahia-Brazil).

\begin{tabular}{|c|c|c|c|c|c|}
\hline & 2014 & 2015 & 2016 & 2017 & Total \\
\hline Total cases ( $\%$ of total for each year) & $42(8.1)$ & $31(6.0)$ & $202(38.8)$ & $245(47.1)$ & $520(100.0)$ \\
\hline Total number of pregnant women served & 4,081 & 5,198 & 4,539 & 2,821 & 16,639 \\
\hline Total number of live births & 3,588 & 3,655 & 3,264 & 2,178 & 12,685 \\
\hline \multicolumn{6}{|l|}{ Syphilis } \\
\hline Cases & 13 & 10 & 173 & 213 & 409 \\
\hline Prevalence at maternity hospital, $\%$ & 0.32 & 0.19 & 3.81 & 7.55 & 2.46 \\
\hline Number of cases per 1,000 live births & 3.62 & 2.74 & 53.0 & 97.8 & 32.2 \\
\hline \multicolumn{6}{|l|}{ AIDS/HIV } \\
\hline Cases & 18 & 17 & 19 & 25 & 79 \\
\hline Prevalence among STI-positive pregnant women & 42.9 & 54.8 & 9.4 & 10.2 & 15.2 \\
\hline Cases & 11 & 4 & 15 & 12 & 43 \\
\hline Prevalence among STI-positive pregnant women & 26.2 & 12.9 & 7.4 & 5.3 & 8.3 \\
\hline Prevalence at maternity hospital, \% & 0.27 & 0.08 & 0.33 & 0.43 & 0.26 \\
\hline Number of cases per 1,000 live births & 3.07 & 1.09 & 4.60 & 5.51 & 3.39 \\
\hline \multicolumn{6}{|l|}{ Hepatitis C } \\
\hline Cases & 3 & 4 & 2 & 1 & 10 \\
\hline Prevalence among STI-positive pregnant women & 7.1 & 12.9 & 1.0 & 0.4 & 1.9 \\
\hline Prevalence at maternity hospital, \% & 0.07 & 0.08 & 0.04 & 0.04 & 0.06 \\
\hline Number of cases per 1,000 live births & 0.84 & 1.09 & 0.61 & 0.46 & 0.79 \\
\hline
\end{tabular}

nationwide, as well as at the local maternity hospital in Salvador, indicating the need for novel approaches to prevention and control. In addition to exposure due to unprotected sex, another pertinent issue is the inadequate distribution of penicillin, commonly used for treatment in Brazil, which likely contributed to greater numbers of untreated patients and infection dissemination. 23 While this phenomenon could partially explain the present results, other factors, such as a lack of information regarding symptoms and disease transmission, scarce investment by health agencies, inadequate monitoring and stigmatization could also have contributed to the estimations reported herein. 15

STI can substantially impact patient health by compromising diverse organs and tissues. In addition, STI can also promote imbalance in the immune response, possibly leading to a lack of homeostatic cytokine production and alterations in the expression of cell receptors and cellular response. 24 With respect to HIV, early diagnosis is extremely important due to the virus' propensity to infect immune cells, thereby inducing consequential immunodeficiency.
Several campaigns aimed at preventing HIV infection have been conducted worldwide. International policies designed to control AIDS demonstrate that by $2020,90 \%$ of individuals living with HIV will be aware of their infection status; the goal is for these individuals to receive uninterrupted antiretroviral treatment, thereby greatly reducing viral load. 25 In 2016, the "U=U" campaign highlighted that indivi-duals with consistently undetectable viral load are unable to transmit HIV, i.e. undetectable equals untransmissible. 26 Nonetheless, an improperly informed population could promote incommensurate concern about HIV and lead to greater exposure as a result of unprotected sexual behavior.

The Global Plan towards the Elimination of New HIV Infections among Children by 2015 and Keeping Their Mothers Alive, launched in 2011, has demonstrated clear progress, especially in its target audience. The 2016 United Nations resolution 25 reported that around 85 countries were closing in on eliminating mother-to-child transmission, yet in 2017 an increasing prevalence of HIV was seen in pregnant women in Brazil, surpassing the estimates 
Rates of HIV, HBV, and HCV per 1,000 live births in pregnant women seen at the Climério de Oliveira maternity hospital (MCO-UFBA) compared to the general population of the State of Bahia, the Brazilian Northeast Region and Brazil as a whole.

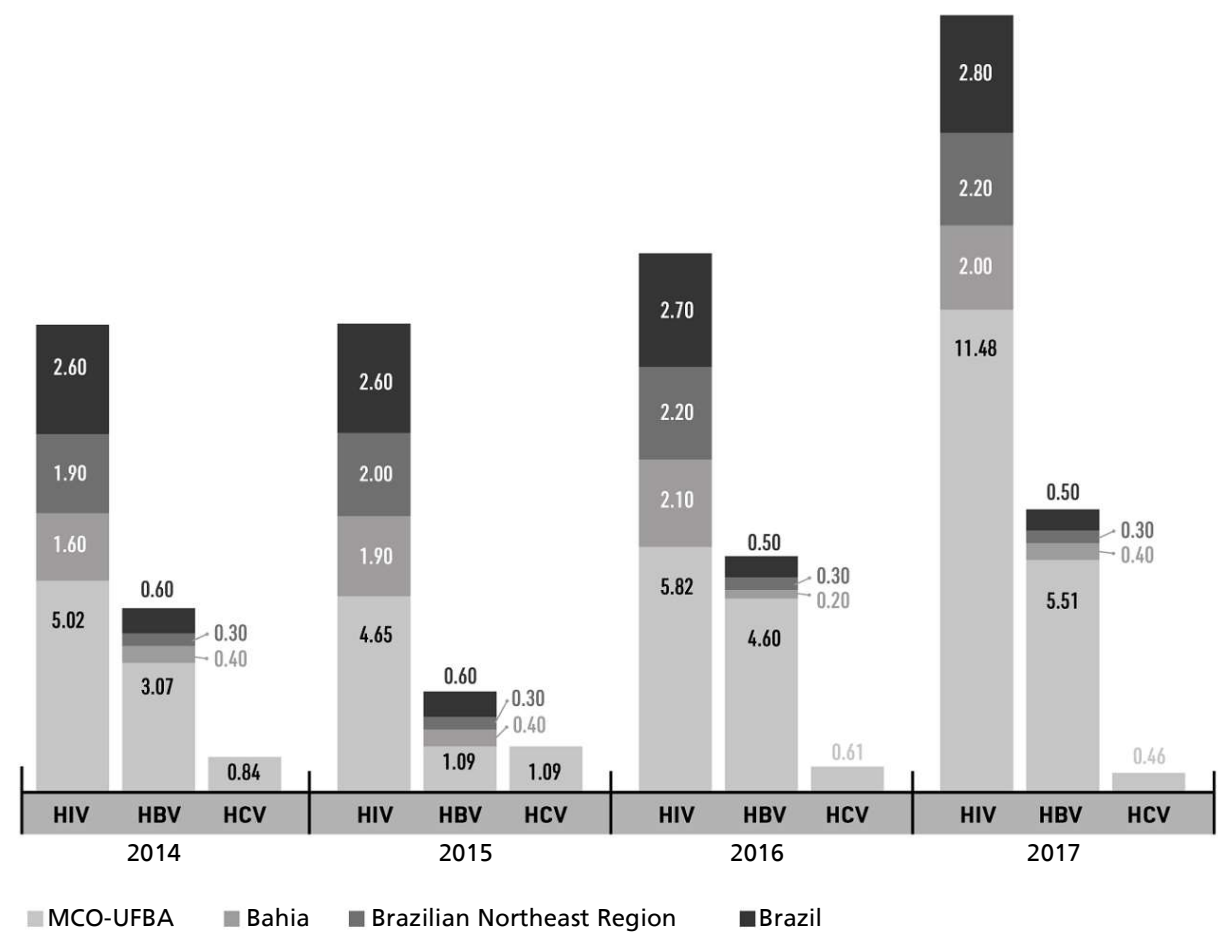

\section{Figure 2}

Rate of syphilis infection per 1,000 live births in pregnant women seen at the Climério de Oliveira maternity hospital (MCO-UFBA) compared to the general population of the state of Bahia, the Brazilian Northeast Region and Brazil as a whole.

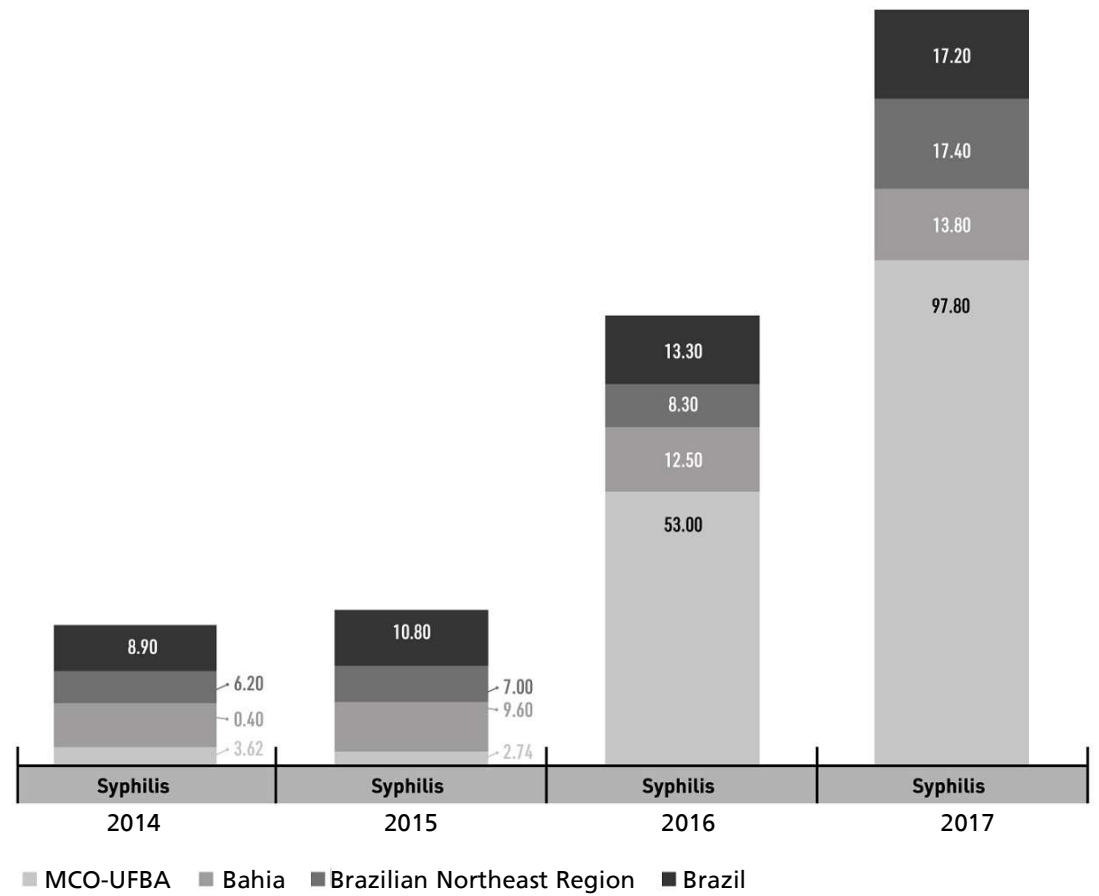


reported in preceding years. ${ }^{27}$ Our analysis of local and national data revealed comparatively increased rates of HIV per 1,000 live births at MCO-UFBA between 2014-2017: 1.93, 1.79, 2.16 and 2.79 times higher (year-by-year, respectively). This finding demonstrates the importance of continued investment in public health policies aimed at controlling and preventing STI, particularly with regard to the surveillance of pregnant women, considering that early antiretroviral treatment is a key factor in controlling VT of HIV.

Viral hepatitis, most notably hepatitis $\mathrm{C}$, has not been well studied in pregnant women. Accordingly, the scientific literature on $\mathrm{HCV}$ in Brazil is lacking with regard to investigations on disease progression and the effects on health for both mothers and children. Concerning HBV, a Chinese study showed that just $23.4 \%$ and $17.7 \%$ of pregnant women were aware of their infection status prior to pregnancy and childbirth, respectively, 28 highlighting the importance of expanding the investigation of this disease in pregnant women. Although we identified relatively low rates of infection, especially for $\mathrm{HCV}$, the dearth of available data on pregnant women warrants further study to elucidate relevant aspects of infection. The lack of studies conducted on this topic serves to exemplify the unavailability of epidemiologic data on HCV infection in pregnant women officially reported by $\mathrm{MoH}$. While it is impossible to establish comparisons between rates of hepatitis $\mathrm{C}$ in pregnant women and the country as a whole, a recent epidemiological bulletin released by $\mathrm{MoH}$ indicated a lower rate of hepatitis C (0.4-15.6 per 100,000 inhabitants) in women of childbearing age (10-49 years) compared to the presented reported rates at MCO-UFBA. ${ }^{4}$ Hepatitis can endanger both maternal health and increase the risk, for the fetus, of infection during pregnancy, 29 justifying the need for additional study of disease despite the relatively low numbers of cases reported.

The compulsory notification of STI, as well as other diseases such as cholera, whooping cough, diphtheria, and leptospirosis, is mandatory practice at all public health care facilities in Brazil, and extends to professionals working at private clinics and/or laboratories. 22 The underreporting of cases hampers the development of policies based on the true rates of these diseases due to underestimations of prevalence. Accordingly, more efficient health care surveillance systems are recommended to provide more reliable data. In addition, the provision of appropriate treatment for diverse STIs is also dependent on the accurate identification of cases. Thus, inefficient surveillance systems can lead to insufficient investment directed at the control of disease.

Social vulnerability can also often lead to difficulty in accessing treatment, as well as an incomplete understanding of the need to comply with follow-up procedures. It is helpful for healthcare professionals and health management team members to be familiar with the particular characteristics of different populations in order to provide suitable and humanized care, and to facilitate the understanding of relevant health aspects by the patients themselves. Despite not being uniformly present in medical records, information regarding sexual partners presents an opportunity to control infection and promote treatment in pregnant women whose newborns could be at risk of VT. Considering that social issues, such as poverty, can negatively impact patients' ability to visit healthcare centers, the proper identification of these factors can aid in establishing mitigation strategies. For instance, the early treatment of HIV infection was proposed as a strategy to combat the spread of AIDS, and the identification of vulnerable populations was essential to the $90-90-90$ target campaign. 16

The present study is importantly limited by the secondary data used in our analysis. Poorly registered information on medical records, as well as missing data on clinical condition and patient risk factors led to gaps in the present database, thereby impeding our ability to more comprehensively analyze behavioral and sociodemographic factors in the pregnant women with STI studied herein. Data on sexual partners, age at time of first sexual intercourse and frequency of exposure to unprotected sex were not investigated due to missing information on most medical records. Differences in data availability between 2014 and 2015 compared to 2016 and 2017 is also noteworthy. The implementation of a surveillance system at MCO-UFBA in 2015 contributed to improved active surveillance strategies at the institution's outpatient services.

The investigation of STI and proper follow-up of pregnant women post-diagnosis is of fundamental importance to the control and prevention of these diseases. Despite the relatively higher number of cases detected at the maternity hospital studied herein compared to national statistics, our results demonstrate the need for improved quality in recording STI-related factors on clinical records. Therefore, we highlight the importance of developing strategies to enhance information quality, as well as the conduct of additional research into regional aspects associated with STI. 


\section{Acknowledgements}

The authors would like to thank the Health Surveillance Team Members at MCO-UFBA, as well as the institution's administration and all patients seen at Climério de Oliveira Maternity Hospital. We additionally thank all our research team members for their contributions and hard work. The authors are grateful to Andris K. Walter for critical analysis and manuscript translation into English.

\section{References}

1. MullickS, Watson-Jones D, Beksinska M, Mabey D Sexually transmitted infections in pregnancy: prevalence, impact on pregnancy outcomes, and approach to treatment in developing countries. Sex Transm Infect.2005; 81: 294 302 .

2. Brasil. Boletim Epidemiológico - Sífilis. vol. 49; 2018.

3. Brasil. Boletim Epidemiológico - HIV AIDS. vol. 49; 2018. Disponível em: http://www.aids.gov.br/pt-br/pub/2018/ boletim-epidemiologico-hivaids-2018

4. Brasil. Boletim Epidemiológico - Hepatites Virais. vol. 49; 2019.

5. Cheung KW, Seto MTY, Lao TT-H. Prevention of perinatal hepatitis B virus transmission. Arch Gynecol Obstetr.2019 300: 251-9.

6. Gambarin-Gelwan M. Hepatitis B in pregnancy. Clin Liver Dis. 2007; 11: 945-63.

7. Brasil. Ministério da Saúde.Protocolo Clínico e Diretrizes Terapêuticas para Prevenção da Transmissão Vertical do HIV, Sífilis e Hepatites Virais; 2019.

8. Connell LE, Salihu HM, Salemi JL, August EM, Weldeselasse H, Mbah AK. Maternal hepatitis B and hepatitis C carrier status and perinatal outcomes. Liver Int. 2011; 31: 1163-70.

9. Safir A, Levy A, Sikuler E Sheiner E. Maternal hepatitis B virus or hepatitis $\mathrm{C}$ virus carrier status as an independent risk factor for adverse perinatal outcome. Liver Int. 2010; 30 (5): 765-70

10. Huang Q-t, Huang Q, Zhong M, Wei S-s, Luo W, Li F, Yu Y-h. Chronic hepatitis $\mathrm{C}$ virus infection is associated with increased risk of preterm birth: a meta-analysis of observational studies. J Viral Hepatitis. 2015; 22: 1033-42.

11. Dunkelberg, J. C., Berkley, E. M. F., Thiel, K. W. \& Leslie, K. K. Hepatitis B and C in pregnancy: a review and recommendations for care. J Perinatol. 2014; 34: 882-91.

12. Benova, L., Mohamoud, Y. A., Calvert, C. \& Abu-Raddad, L. J. Vertical Transmission of Hepatitis C Virus: Systematic Review and Meta-analysis. Clin Infect Dis. 2014; 59: 765-73.

13. Aebi-Popp K, Duppenthaler A, Rauch A, de Gottardi A, Kahlert C. Vertical transmission of hepatitis C: towards universal antenatal screening in the era of new direct acting antivirals (DAAs)? Short review and analysis of the situation in Switzerland. J Virus Erad. 2016; 2 (1): 52-4

14. Jonas MM. Children with hepatitis C. Hepatology. 2002. 36

\section{Author's contribution}

The manuscript was written by Freire JO, Schuch JB, Roglio VS, von DiemenL, and the final version was revised by all coauthors. Data collection and database creation was performed by Freire JO, Miranda MF, Tanajura H, Victa AGLB. Statistical analysis was performed by Roglio VS. Study design was conceived by JO and von DiemenL. All authors approved the final version of the article.

(5 Supl. 1): s173-8.

15. WHO (World Health Organization). Report on global sexually transmitted infection surveillance; 2018.

16. UNAIDS. 2015 Progress Report on the GLOBAL PLAN. Unaids vol. 11 http://www.unaids.org/sites/default/files/media_asset/JC27 74 2015ProgressReport GlobalPlan en.pdf\%0Ahttp://ww w.unaids.org/sites/default/files/media_asset/JC2774_2015P rogressReport_GlobalPlan_en.pdf\%0Ahttp://www.ncbi.nl m.nih.gov/pubmed/27355509\%5Cnhttp://w (2015).

17. PAHO (Pan American Health Organization). Elimination of mother-to-child transmission of HIV and syphilis in the Americas. Washington, DC; 2017. Disponível em: https://iris.paho.org/bitstream/handle/10665.2/34072/97892 75119556-eng.pdf

18. Watson-Jones D, Changalucha J, Gumodoka B, Weiss H, et al. Syphilis in Pregnancy in Tanzania. I. Impact of Maternal Syphilis on Outcome of Pregnancy. J Infect Dis. 2002; 186 (7): 940-7.

19. Schulz K F, Cates W, O’Mara PR. Pregnancy loss, infant death, and suffering: legacy of syphilis and gonorrhoea in Africa. Genitourin Med. 1987; 63 (5): 320-5.

20. Freire JO. Banco de dados para pesquisadores de gestantes atendidas com Infecções Sexualmente Transmissíveis na Maternidade Climério de Oliveira, Brasil. (2019) doi:10.6084/m9.figshare.8947436.v5

21. Freitas CHSM,Forte FDS, Roncalli AG, et al. Factors associated with prenatal care and HIV and syphilis testing during pregnancy in primary health care. Rev Saúde Pública. 2019; 53: 76.

22. Brasil. Ministério da Saúde. Portaria no 204, de 17 de fevereiro de 2016. Define a Lista Nacional de Notificação Compulsória de doenças, agravos e eventos de saúde pública nos serviços de saúde públicos e privados em todo o território nacional, nos termos do anexo, e dá outras providências. [acesso em 11 jan 2021]. Disponível em https://portalarquivos2.saude.gov.br/images/pdf/2018/abril/ 25/Portaria-n---2014-de-17--Fevereiro-2016.pdf.

23. Brasil. Ministério da Saúde. Nota Informativa Conjunta $\mathrm{n}^{\circ}$ 109/105/GAB/SVS/MS, GAB/SCTIE/MS; 2015.

24. Vickers DM, Osgood ND. A unified framework of immunological and epidemiological dynamics for the spread of viral infections in a simple network-based population. Theor Biol Med Model. 2007; 4: 1-13. 
25. UNO. Political Declaration on HIV and AIDS: On the FastTrack to Accelerate the Fight against HIV and to End the AIDS Epidemic by 2030. Unaids vol. 17020 http://web.ua.es/es/ice/documentos/redes/2012/asesoramiento/modelo-normas-apa-bibliografia.pdf (2016).

26. The Lancet HIV. U $=\mathrm{U}$ taking off in 2017 [Editorial]. Lancet HIV.2017; 4 (11): e475.

27. Domingues RMSM, Szwarcwald CL, Borges Souza PR, Leal MC. Prenatal testing and prevalence of HIV infection during pregnancy: Data from the "Birth in Brazil" study, a national hospital-based study. BMC Infect Dis. 2015; 15: 100 .

Received on September, 2020

Final version presented on February 1, 2021

Approved on May 20, 2021
28. Sheng Q-J, Wang S-J, Wu Y-Y, Dou X-G, Ding Y. Hepatitis $B$ virus serosurvey and awareness of mother-to-child transmission among pregnant women in Shenyang, China. Medicine.2018; 97: e10931.

29. Castillo E, Murphy K, van Schalkwyk J. No. 342-Hepatitis B and Pregnancy. J Obstet Gynaecol Can. 2017; 39: 18190 . 